\title{
A cluster analysis of patterns of objectively measured physical activity in Hong Kong
}

\author{
Paul H Lee ${ }^{1}$, Ying-Ying Yu ${ }^{1}$, lan McDowell ${ }^{2}$, Gabriel M Leung ${ }^{1}$ and TH Lam ${ }^{1, *}$ \\ ${ }^{1}$ FAMILY: A Jockey Club Initiative for a Harmonious Society, School of Public Health/Department of Community \\ Medicine, Room 5-05, 5/F William MW Mong Block, 21 Sassoon Road, Li Ka Shing Faculty of Medicine, \\ University of Hong Kong, Hong Kong SAR, People's Republic of China: ${ }^{2}$ Department of Epidemiology and \\ Community Medicine, University of Ottawa, Ottawa, Ontario, Canada
}

Submitted 8 February 2012: Final revision received 5 June 2012: Accepted 26 June 2012: First published online 16 August 2012

\begin{abstract}
Objective: The health benefits of exercise are clear. In targeting interventions it would be valuable to know whether characteristic patterns of physical activity (PA) are associated with particular population subgroups. The present study used cluster analysis to identify characteristic hourly PA patterns measured by accelerometer.

Design: Cross-sectional design.

Setting: Objectively measured PA in Hong Kong adults.

Subjects: Four-day accelerometer data were collected during 2009 to 2011 for

1714 participants in Hong Kong (mean age $44 \cdot 2$ years, $45 \cdot 9 \%$ male).

Results: Two clusters were identified, one more active than the other. The active cluster' ( $n$ 480) was characterized by a routine PA pattern on weekdays and a more active and varied pattern on weekends; the other, the 'less active cluster' ( $n$ 1234), by a consistently low PA pattern on both weekdays and weekends with little variation from day to day. Demographic, lifestyle, PA level and health characteristics of the two clusters were compared. They differed in age, sex, smoking, income and level of PA required at work. The odds of having any chronic health conditions was lower for the active group (adjusted OR $=0 \cdot 62$, $95 \%$ CI $0 \cdot 46,0 \cdot 84)$ but the two groups did not differ in terms of specific chronic health conditions or obesity.

Conclusions: Implications are drawn for targeting exercise promotion programmes at the population level.
\end{abstract}

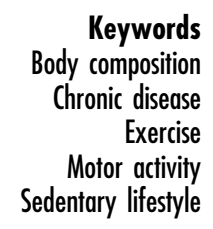

The health benefits of regular physical activity (PA) are well established ${ }^{(1)}$, including positive associations with psychological well-being $^{(2,3)}$ and an inverse relationship with various illnesses ${ }^{(4,5)}$. However, general efforts to promote exercise have met limited success; potentially more specifically targeted interventions may prove more effective. To plan these, we need information on population patterns of PA to examine whether there are identifiable groups for whom interventions should be tailored and also to better estimate the impact of such interventions. Several such studies have been conducted, including cohort studies of PA levels, patterns in children and adolescents ${ }^{(6-9)}$ and population-level comparisons between countries ${ }^{(10)}$.

Examination of PA patterns requires a reliable and valid measure of PA. While many studies have relied on self-report questionnaires ${ }^{(11,12)}$, their validity is questionable $^{(13,14)}$. On the other hand, accelerometers offer an objective and reliable measurement ${ }^{(15)}$ and are therefore increasingly popular in research. These electronic devices are worn by the subject to record accelerations in movement to indicate the duration and intensity of PA. a specified threshold, sometimes termed an 'activity count ${ }^{(16)}$. Most studies report average daily counts and/or total time spent on $\mathrm{PA}^{(10,16,17)}$, but this does not reveal the temporal pattern of PA, such as whether the activity is concentrated in certain periods of the day. Some researchers noted this as a limitation and they have recorded bouts of $\mathrm{PA}^{(10,17)}$. However this method is also has its limitation in not distinguishing the time patterns of PA. Only by looking at PA patterns can we compare the relative effect of the duration and intensity of PA; for example, comparing the benefits of brief but intensive PA with less-intensive activities of longer duration, or whether PA occurring in the morning and at night has similar effects on health. Furthermore, with a better understanding of PA patterns, one can tailor health programmes more precisely to the needs of people who exhibit specific characteristic PA patterns. Most accelerometers count accelerations larger than 
We present a population study of hourly PA patterns on weekdays and weekends in urban Hong Kong. To compress the large amount of data produced from the accelerometer readings, we applied a cluster analysis to group people with similar PA patterns ${ }^{(18)}$. This reveals distinct PA patterns and the clusters can be compared in terms of the people's characteristics in each cluster, including their health status. Cluster analysis has previously been used to provide daily summaries of PA, but only with questionnaire data ${ }^{(19,20)}$; ours appears to be the first study to have applied cluster analysis to accelerometer data. Whereas previous studies have provided daily summaries of PA patterns using accelerometer data ${ }^{(9,21)}$, we extend this by analysing hourly PA patterns.

\section{Methods}

\section{Participants}

The present study was part of the Hong Kong Jockey Club FAMILY Project Cohort Study, funded as an initiative to promote family health, happiness and harmony in Hong Kong. It includes families recruited during March 2009 to January 2011. Sampling was based on a random selection of residential addresses provided by the Hong Kong Census and Statistics Department. A family was eligible when all members aged 15 years or older, who lived in the same address and could understand Cantonese, agreed to participate. All eligible members were interviewed by trained interviewers who entered the data into tablet personal computers. Details of the interview have been described elsewhere ${ }^{(22)}$. Having completed the main survey ( $n$ 45767), randomly chosen participants ( $n$ 32530) were invited to take part in a sub-study by wearing an accelerometer for four consecutive days (including a weekend). Written consent was obtained from participants (parental consent was also obtained for participants under 18 years old) and the study was approved by the Institutional Review Board of the University of Hong Kong.

\section{Measurements}

\section{Accelerometer}

Previous studies have found the ActiGraph to be reliable and valid ${ }^{(15,23-25)}$. A recent study ${ }^{(26)}$ showed that $1 \mathrm{~d}$ of accelerometer data is adequate for estimating weekly moderate-to-vigorous PA (MVPA) in a representative US sample aged 20-85 years but we adopted a more stringent criterion because we aimed to examine hourly PA patterns. A total of 5898 participants agreed to participate and were instructed to wear an ActiGraph GT1 M uniaxial accelerometer (http://www.theactigraph.com). The ActiGraph was to be worn around the hip (right hip for right-handed and left hip for left-handed persons) for four consecutive days for all waking hours, removed only when bathing or sleeping. Instead of the conventional $7 \mathrm{~d}$ requirement, a $4 \mathrm{~d}$ measurement period was chosen to reduce user burden and encourage participation; two weekdays and two weekend days were selected on the assumption that there should be relatively little variation across weekdays. The choice of the start day (Thursday, Friday or Saturday) was up to the participant.

'Non-wear' time was defined by an interval of zero accelerometer counts for sixty consecutive minutes or more. 'Wearing' time in a day was computed by subtracting non-wear time from $24 \mathrm{~h}$. A valid day had to include at least $12 \mathrm{~h}$ of wearing time. Only observations with four valid days of data were accepted for analysis ${ }^{(26)}$. While previous studies used a threshold of at least $10 \mathrm{~h}$ of registered time/d to report daily $\mathrm{PA}^{(9,27)}$, we again adopted a more stringent criterion of $12 \mathrm{~h} / \mathrm{d}$.

Counts were recorded using a 1 min epoch. PA level was assessed with counts per minute, i.e. total counts divided by $(60 \times \text { number of wearing hours })^{(10,16)}$, and separated into time spent on MVPA and light PA (LPA) ${ }^{(28)}$. A 1 min period was classified as MVPA ( $\geq 3.00$ metabolic equivalent tasks, MET) if the total counts within this period were greater than or equal to $1952^{(29)}$, and was classified as LPA if the total counts ranged between 101 and 1951 (inclusive). The time spent on MVPA and LPA was the total number of moderate-to-vigorous minutes and light minutes in a day. The ActiGraph firmware version $7 \cdot 5 \cdot 0$ was used for data transformation.

The $k$-means cluster analysis ${ }^{(18,30)}$ was used to identify the number of distinct hourly PA patterns. Average counts per minute from 00.00 hours to 23.59 hours on both weekdays and weekends were used as cluster variables. This gave a total of forty-eight cluster variables (twentyfour for weekdays, twenty-four for weekends), allowing us to identify different PA patterns for weekdays and weekends. All cluster variables were standardized to a mean of 0 and a variance of 1 to equalize the importance of each variable. First, $k$ (a pre-specified integer) cluster centres were randomly generated. Next, the Euclidean distance was computed between participant $i$ and cluster centre $j$, which equals

$$
\sqrt{\sum_{t=1}^{24}\left(d_{t, i}-d_{t, j}\right)^{2}+\left(e_{t, i}-e_{t, j}\right)^{2}},
$$

where $d$ and $e$ are the standardized average counts per minute in hour $t$ on weekdays and weekends, respectively, for all centres $j=1$ to $k$. Participant $i$ was assigned to his or her nearest cluster (i.e. one with the shortest distance). After assigning all participants to their nearest cluster, the new cluster centres were recomputed using their mean, after which these steps were iterated until convergence was reached. The elbow method was used to determine the number of clusters and the pseudo $R$-square and Mann-Whitney $U$ tests were used to assess the goodness-of-fit of the final cluster solution. To select 
an appropriate $k$, within-cluster sum of squares distances were computed for $k=2$ to 10 , and $k$ was determined using the elbow method (i.e. a sudden drop of withincluster sum of squares distances from $k-1$ to $k$ indicates $k$ as the appropriate solution) ${ }^{(31)}$. A dendrogram was then used to confirm the number of clusters obtained using the elbow method. Non-parametric (Kruskal-Wallis) tests were used because the forty-eight cluster variables were not normally distributed $(P<0 \cdot 001$ for Kolmogorov-Smirnov normality tests).

\section{Chronic health conditions}

Participants were asked whether a medical practitioner had told them that they had any of eight chronic health conditions chosen to represent relatively definitive diagnoses: cancer, diabetes mellitus, hypertension, high cholesterol, heart disease, stroke, asthma or chronic obstructive pulmonary disease. We also recorded self-reported medicine use for those who reported a chronic health condition, to permit some validation of the reported chronic conditions.

\section{Body composition}

Height (with SECA 214 stadiometer, http://www.seca.com), weight and body fat percentage (BFP; using the Omron fat analyser scale HBF-356, http://www.omron-healthcare. com.sg) were measured by trained interviewers following standard protocols. BMI was calculated as weight $(\mathrm{kg})$ divided by the square of height $\left(\mathrm{m}^{2}\right)$. Two definitions of obesity, based on BFP or BMI, were used in the present study. Obesity by BFP was defined as $\geq 25 \%$ (males) and $\geq 35 \%$ (females). Obesity by BMI was defined as $\geq 30 \mathrm{~kg} / \mathrm{m}^{2}$.

\section{Other statistical analyses}

A comparison of self-reported chronic conditions and self-reported medication use indicated that $95 \%$ of the people reporting a chronic condition were taking medication(s) that corresponded to that condition. Subsequent analyses comparing activity levels to chronic conditions were restricted to this sub-set of participants.

Outliers with ActiGraph counts per minute $(\geq$ median + $1.5 \times$ interquartile range) were removed ( $n$ 617) before the cluster analysis ${ }^{(32)}$. Outliers did not differ in terms of demographic variables (all $P>0 \cdot 05$ ). For interval-scaled variables such as age and BMI, independent $t$ tests were used to compare the differences between clusters and Cohen's $d^{(33)}$ was used to assess the effect size of these differences. Effect sizes of $0 \cdot 2,0 \cdot 5$ and 0.8 were classified as small, medium and large, respectively ${ }^{(33)}$. For categorical variables, Pearson's $\chi^{2}$ test was used to compare the differences between clusters. For the prevalence of chronic health conditions, odds ratios, unadjusted and adjusted for age, sex, smoking, education and income, were used to compare the differences between clusters. All statistical analyses were performed using Predictive Analytics SoftWare (PASW 18・0, formerly known as SPSS).

\section{Results}

\section{Cluster analysis}

Analysable accelerometer data were obtained from a total of 1740 participants. The average of 1128 correlations for the forty-eight hourly variables was $0 \cdot 09$. Among those, only nine pairs $(0 \cdot 8 \%)$ had a correlation larger than 0.5 , ruling out multicollinearity among the forty-eight variables. A four-cluster solution was obtained using both the elbow method and the dendrogram (Fig. 1). It showed that, when the number of clusters increased from two to four, the within-cluster sums of squares were large. However, two clusters had a sample size of twenty or less. Upon further examination, one cluster ( $n$ 20) showed constant PA for the entire $24 \mathrm{~h}$ period, evidently an error; and the other included only six people. These twenty-six participants were removed, leaving 1714 participants, 480 (28\%) in cluster 1 (the 'active') and 1234 (72\%) in cluster 2 (the 'less active'). We did not find groups of people who were active only on the weekend but not during the week (or vice versa), which if present would have formed other distinct clusters. The pseudo $R$-square and Mann-Whitney $U$ test $z$-values for each of the forty-eight hourly variables ranged from $0 \cdot 01 \%$ to $19 \cdot 92 \%$ (mean $7 \cdot 57 \%$ ) and from $0 \cdot 26$ to $17 \cdot 54$ (mean 8.71), respectively. Thirty-five out of the forty-eight Mann-Whitney $U$ tests were significant at the $5 \%$ level.

\section{Chster physical activity profile}

Figures 2 and 3 show weekday and weekend PA patterns, respectively, for the two clusters, as well as the average level. First, with respect to the overall PA patterns (solid lines in Figs 2 and 3) there was a slightly greater hourly variation on weekdays than on weekends. Slight increases in counts per minute were observed on weekdays during 08.00-08.59, 13.00-13.59 and 18.00-18.59 hours, most likely corresponding to times of commuting to and from work, and going to lunch. On weekends (Fig. 3, solid line), the overall PA trend was comparatively smooth between 11.00 and 18.59 hours.

Second, on weekdays, both clusters showed similar temporal PA patterns, differing only in intensity. By contrast, the two groups showed different patterns on the weekend. For cluster 1, activity peaks were found at 10.00-10.59, 16.00-16.59 and 19.00-19.59 hours, suggesting periods of increased PA. For cluster 2, the hourly PA curve on weekends was low and smooth, suggesting no increased PA or sports activity. In sum, participants of cluster 1 were generally more active and showed a more varied PA pattern on weekends than those of cluster 2.

PA levels are summarized in Table 1 . The overall average count per minute was $310 \cdot 9$. The participants spent 22.5 and $247.5 \mathrm{~min} / \mathrm{d}$ on MVPA and on LPA, respectively. Participants were in general more active on weekdays than on weekends (323.6 v. 297.2 counts/min). They also spent slightly more time on MVPA on weekdays 


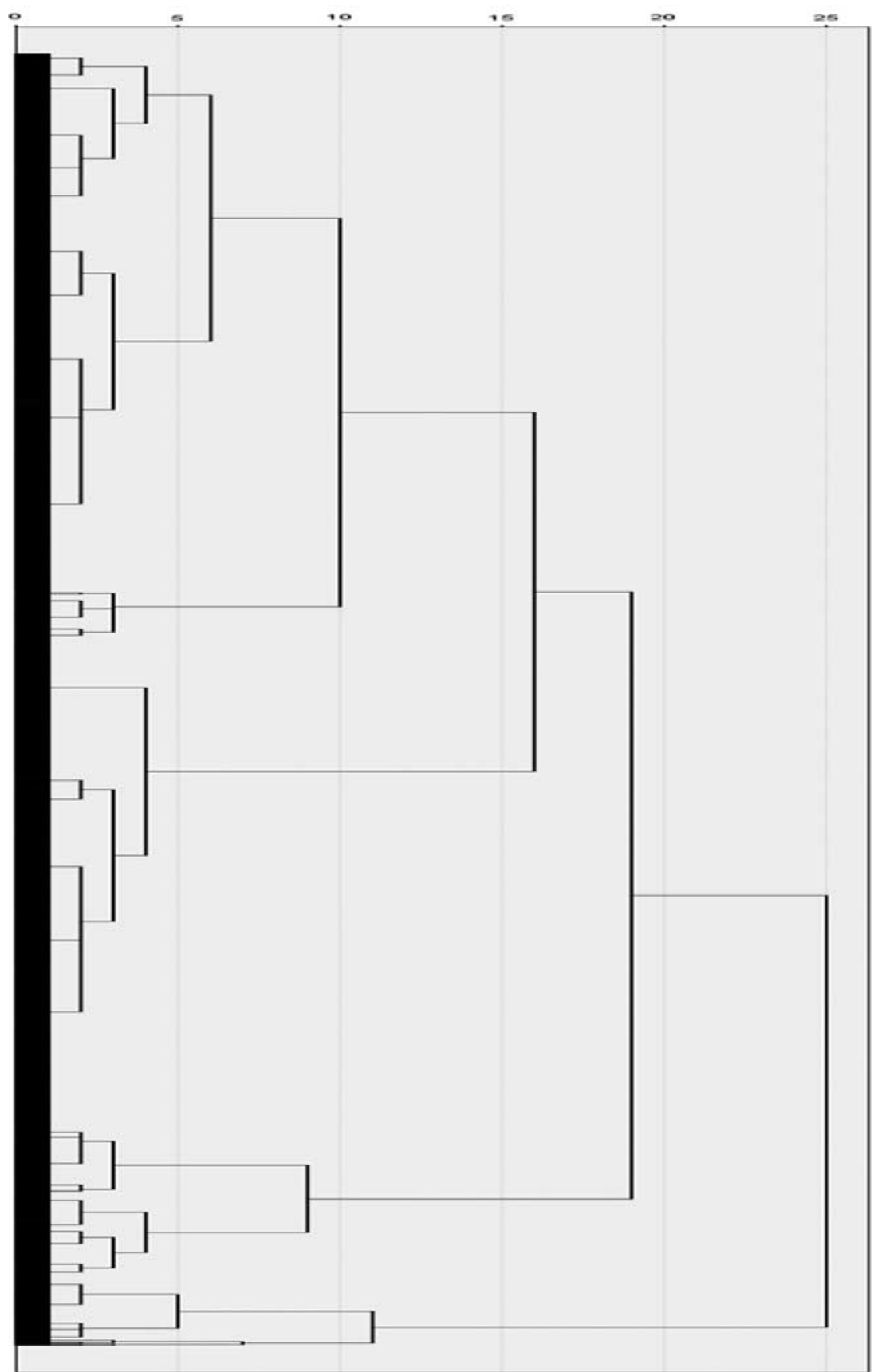

Fig. 1 Dendrogram of the cluster analysis solution

than on weekends $(23 \cdot 1 v .20 \cdot 9 \mathrm{~min} / \mathrm{d})$ and less time on LPA on weekdays than on weekends $(242 \cdot 1 v .260 \cdot 9 \mathrm{~min} / \mathrm{d})$. These differences were observed among participants in both clusters.

There were large differences between the two clusters in terms of counts per minute $(456.4 v .252 \cdot 0$ counts $/ \mathrm{min}$, $d=1 \cdot 62)$, daily MVPA minutes $(35 \cdot 4 v .17 \cdot 5 \mathrm{~min} / \mathrm{d}, d=1 \cdot 28)$ and daily LPA minutes $(319 \cdot 0 v .219 \cdot 7 \mathrm{~min} / \mathrm{d}, d=0 \cdot 82)$. An active participant (accumulating $150 \mathrm{~min} \mathrm{MVPA} /$ week as recommended by the Centers for Disease Control and Prevention/American College of Sports Medicine) ${ }^{(11)}$ had $4 \cdot 18$ times the odds (95\% CI $2 \cdot 75,6 \cdot 37)$ of being in the active cluster.

\section{Demographic profiles of the clusters}

Table 2 shows that people in the active cluster were heavier and had lower BFP than those in the less active cluster. After adjusting for sex, however, there was no difference in BFP between the two clusters. Compared with the less active group, males in the active group had lower BFP $(22.3 \%$ v. $23.5 \%$ in the less active group, $P<0 \cdot 05)$, were shorter $(165 \cdot 0 \mathrm{~cm} v .167 \cdot 3 \mathrm{~cm}$ in the less 


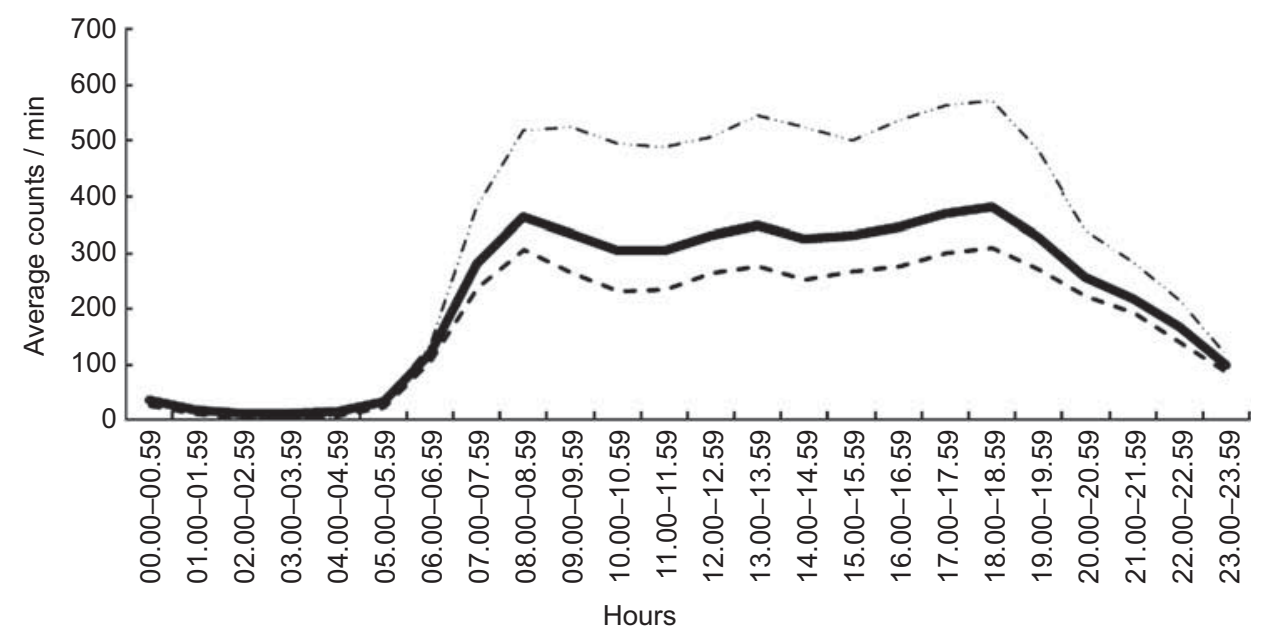

Fig. 2 Hourly physical activity pattern in the FAMILY Project Cohort Study, Hong Kong, 2009 (weekdays): ——, overall; $-\cdots-\cdots-$, cluster 1 (active); - - cluster 2 (less active)

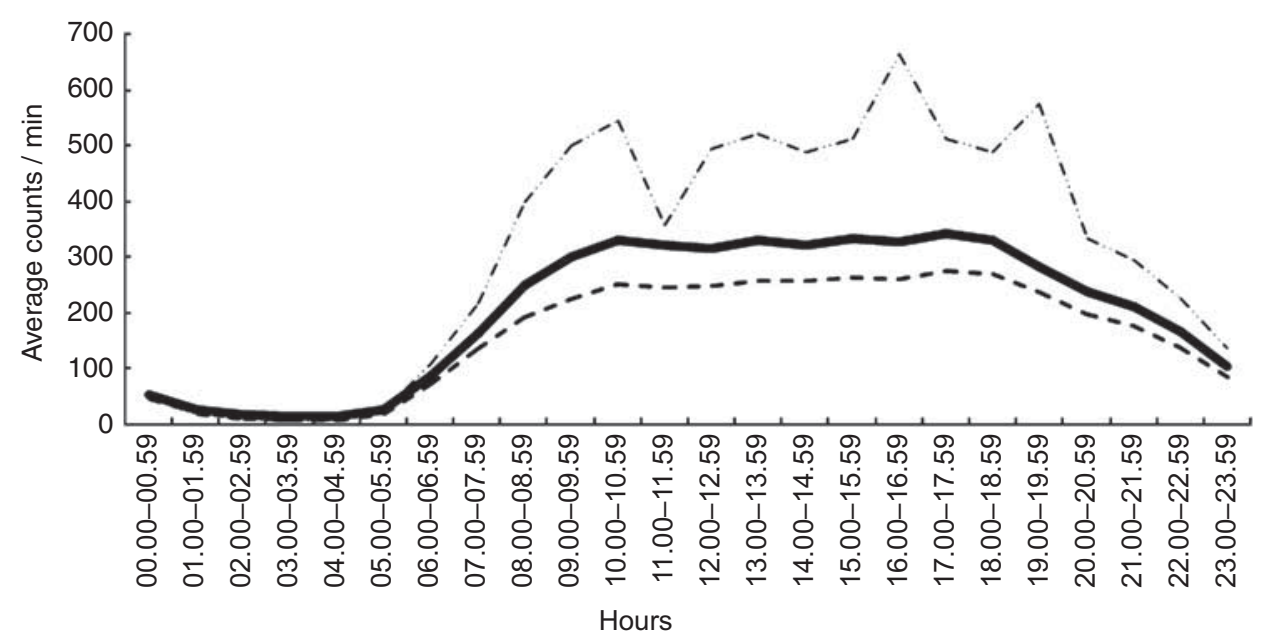

Fig. 3 Hourly physical activity pattern in the FAMILY Project Cohort Study, Hong Kong, 2009 (weekends): - - - - - cluster 1 (active); - - -, cluster 2 (less active)

Table 1 Summary of physical activity levels of the 1714 participants in the FAMILY Project Cohort Study, Hong Kong, 2009

\begin{tabular}{|c|c|c|c|c|c|c|c|}
\hline \multirow[b]{2}{*}{ Variable } & \multicolumn{2}{|c|}{$\begin{array}{l}\text { Overall } \\
(n 1714)\end{array}$} & \multicolumn{2}{|c|}{$\begin{array}{c}\text { Cluster } 1 \\
\text { (active; } n \text { 480) }\end{array}$} & \multicolumn{2}{|c|}{$\begin{array}{c}\text { Cluster } 2 \\
\text { (less active; } n \text { 1234) }\end{array}$} & \multirow[b]{2}{*}{ Effect size } \\
\hline & Mean & SD & Mean & SD & Mean & SD & \\
\hline PA counts/min (overall) & $309 \cdot 2$ & $125 \cdot 1$ & $456 \cdot 4+t+$ & $116 \cdot 0$ & $252 \cdot 0$ & $69 \cdot 2$ & $1 \cdot 62$ \\
\hline PA counts/min (weekday) & $323 \cdot 6^{\star \star \star}$ & $147 \cdot 8$ & $470 \cdot 4^{\star \star \star}, \mathrm{t \dagger \dagger}$ & $144 \cdot 4$ & $266 \cdot 5^{\star \star \star}$ & $103 \cdot 1$ & $1 \cdot 37$ \\
\hline PA counts/min (weekend) & $297 \cdot 2$ & $140 \cdot 1$ & $443 \cdot 2 t+t$ & $144 \cdot 3$ & $240 \cdot 5$ & $87 \cdot 7$ & $1 \cdot 44$ \\
\hline Effect size & \multicolumn{2}{|c|}{$0 \cdot 21$} & \multicolumn{2}{|c|}{0.23} & \multicolumn{2}{|c|}{0.38} & \\
\hline MVPA min/d (overall) & $22 \cdot 5$ & $14 \cdot 0$ & $35 \cdot 4+t+$ & $15 \cdot 7$ & $17 \cdot 5$ & $9 \cdot 3$ & $1 \cdot 28$ \\
\hline MVPA $\mathrm{min} / \mathrm{d}$ (weekday) & $23 \cdot 1^{\star \star \star}$ & $15 \cdot 9$ & $35 \cdot 9^{*}, t+\dagger$ & $18 \cdot 7$ & $18 \cdot 1^{\star \star \star}$ & $11 \cdot 2$ & $1 \cdot 12$ \\
\hline MVPA min/d (weekend) & $20 \cdot 9$ & $15 \cdot 3$ & $33 \cdot 9+t t$ & $17 \cdot 8$ & $15 \cdot 8$ & $10 \cdot 5$ & $1 \cdot 18$ \\
\hline Effect size & \multicolumn{2}{|c|}{$0 \cdot 16$} & \multicolumn{2}{|c|}{$0 \cdot 13$} & \multicolumn{2}{|c|}{0.25} & \\
\hline
\end{tabular}

PA, physical activity; MVPA, moderate-to-vigorous physical activity.

Mean values were significantly different from those at the weekend: ${ }^{\star} P<0.05,{ }^{\star \star \star} P<0.001$.

Mean values were significantly different from those of cluster 2 : $+++P<0.001$.

active group, $P<0 \cdot 05)$ and younger $(41 \cdot 2$ years $v .44 \cdot 3$ years in the less active group, $P<0 \cdot 05)$, but these differences were not found among females.
The demographics of the participants (Table 3) were similar to those of the Hong Kong population $(46 \cdot 0 \%$ male; $39 \cdot 7 \%$ had an income lower than \$HK 10000 ; 
Table 2 Age and body composition measurements for the 1714 participants in the FAMILY Project Cohort Study, Hong Kong, 2009

\begin{tabular}{|c|c|c|c|c|c|c|c|}
\hline \multirow[b]{2}{*}{ Variable } & \multicolumn{2}{|c|}{$\begin{array}{l}\text { Overall } \\
(n 1714)\end{array}$} & \multicolumn{2}{|c|}{$\begin{array}{c}\text { Cluster } 1 \\
\text { (active; } n \text { 480) }\end{array}$} & \multicolumn{2}{|c|}{$\begin{array}{c}\text { Cluster } 2 \\
\text { (less active; } n \text { 1234) }\end{array}$} & \multirow[b]{2}{*}{ Effect size } \\
\hline & Mean & SD & Mean & SD & Mean & SD & \\
\hline Age (years) & $43 \cdot 2$ & $16 \cdot 4$ & $42 \cdot 1$ & $14 \cdot 9$ & $43 \cdot 7$ & $17 \cdot 0$ & $-0 \cdot 10$ \\
\hline Weight (kg) & $60 \cdot 4$ & $12 \cdot 9$ & $61 \cdot 4 t$ & $13 \cdot 1$ & $60 \cdot 0$ & $12 \cdot 9$ & $0 \cdot 11$ \\
\hline Height (cm) & $160 \cdot 5$ & $9 \cdot 3$ & $160 \cdot 8$ & $9 \cdot 8$ & $160 \cdot 5$ & $9 \cdot 1$ & 0.03 \\
\hline BMI $\left(\mathrm{kg} / \mathrm{m}^{2}\right)$ & $23 \cdot 8$ & $3 \cdot 8$ & $24 \cdot 1$ & $3 \cdot 8$ & $23 \cdot 7$ & $3 \cdot 9$ & $0 \cdot 11$ \\
\hline BFP & $26 \cdot 9$ & $8 \cdot 1$ & $25 \cdot 6 t$ & $8 \cdot 2$ & $27 \cdot 4$ & $8 \cdot 1$ & $0 \cdot 22$ \\
\hline
\end{tabular}

BFP, body fat percentage.

Mean values were significantly different from those of cluster 2 : $+P<0.05$.

Table 3 Demographic and lifestyle characteristics of the 1714 participants in the FAMILY Project Cohort Study, Hong Kong, 2009

\begin{tabular}{|c|c|c|c|c|c|c|}
\hline \multirow[b]{2}{*}{ Variable } & \multirow[b]{2}{*}{ Category } & \multirow{2}{*}{$\begin{array}{l}\text { Overall } \\
(n 1714)\end{array}$} & \multicolumn{2}{|c|}{$\begin{array}{c}\text { Cluster } 1 \\
\text { (active; } n \text { 480) }\end{array}$} & \multicolumn{2}{|c|}{$\begin{array}{c}\text { Cluster } 2 \\
\text { (less active; } n \text { 1234) }\end{array}$} \\
\hline & & & $n$ & Column \% & $n$ & Column \% \\
\hline \multirow[t]{6}{*}{ Age group, years $\left(\chi^{2}=32 \cdot 94 t+t\right)$} & $15-24$ & 264 & 66 & $13 \cdot 8$ & 198 & $16 \cdot 0$ \\
\hline & $25-34$ & 224 & 58 & $12 \cdot 1$ & 166 & $13 \cdot 5$ \\
\hline & $35-44$ & 352 & 115 & $24 \cdot 0$ & 237 & $19 \cdot 2$ \\
\hline & $45-54$ & 454 & 156 & $32 \cdot 5$ & 298 & $24 \cdot 1$ \\
\hline & $55-64$ & 258 & 63 & $13 \cdot 1$ & 195 & $15 \cdot 8$ \\
\hline & $\geq 65$ & 162 & 22 & $4 \cdot 6$ & 140 & $11 \cdot 3$ \\
\hline \multirow[t]{2}{*}{$\operatorname{Sex}\left(\chi^{2}=35 \cdot 82 t+t\right)$} & Male & 788 & 276 & $57 \cdot 5$ & 512 & $41 \cdot 5$ \\
\hline & Female & 926 & 204 & $42 \cdot 5$ & 722 & $58 \cdot 5$ \\
\hline \multirow[t]{5}{*}{ Education level $\left(\chi^{2}=8 \cdot 25\right)$} & Primary school & 282 & 83 & $20 \cdot 6$ & 199 & $19 \cdot 7$ \\
\hline & Secondary school & 788 & 233 & $58 \cdot 0$ & 555 & $54 \cdot 8$ \\
\hline & Post-secondary school & 122 & 38 & $9 \cdot 5$ & 84 & $8 \cdot 3$ \\
\hline & University level & 222 & 48 & 11.9 & 174 & $17 \cdot 2$ \\
\hline & Missing§ & 300 & 78 & - & 222 & - \\
\hline \multirow[t]{4}{*}{ Smoking $\left(\chi^{2}=7 \cdot 63 t\right)$} & Yes & 184 & 68 & $16 \cdot 8$ & 116 & $11 \cdot 5$ \\
\hline & Had quit & 60 & 18 & $4 \cdot 5$ & 42 & $4 \cdot 1$ \\
\hline & No & 1173 & 318 & $78 \cdot 7$ & 855 & $84 \cdot 4$ \\
\hline & Missing§ & 297 & 76 & & 221 & \\
\hline \multirow[t]{4}{*}{ Drinking $\left(\chi^{2}=1 \cdot 66\right)$} & Yes & 437 & 137 & $34 \cdot 0$ & 300 & $29 \cdot 7$ \\
\hline & Had quit & 32 & 9 & $2 \cdot 2$ & 23 & $2 \cdot 3$ \\
\hline & No & 944 & 257 & $63 \cdot 8$ & 687 & $68 \cdot 0$ \\
\hline & Missing & 301 & 77 & - & 224 & - \\
\hline \multirow{6}{*}{$\begin{array}{l}\text { Monthly personal income, } \$ \mathrm{HK} \ddagger \\
\left(\chi^{2}=39 \cdot 20+t+\right)\end{array}$} & $1-5000$ & 472 & 93 & $24 \cdot 0$ & 379 & $39 \cdot 0$ \\
\hline & $5001-10000$ & 293 & 116 & $30 \cdot 0$ & 177 & $18 \cdot 2$ \\
\hline & $10001-15000$ & 230 & 76 & $19 \cdot 6$ & 154 & $15 \cdot \overline{8}$ \\
\hline & $15001-20000$ & 127 & 39 & $10 \cdot 1$ & 88 & $9 \cdot 0$ \\
\hline & $>20000$ & 238 & 63 & $16 \cdot 3$ & 175 & $18 \cdot 0$ \\
\hline & Missing & 354 & 93 & - & 261 & - \\
\hline \multirow{6}{*}{$\begin{array}{l}\text { Physical activity required at work } \\
\qquad\left(\chi^{2}=143 \cdot 50+t+\right)\end{array}$} & No full-time job & 478 & 88 & $21 \cdot 9$ & 390 & $38 \cdot 6$ \\
\hline & Not physically demanding & 458 & 90 & $22 \cdot 4$ & 368 & $36 \cdot 4$ \\
\hline & Somewhat physically demanding & 315 & 128 & $31 \cdot 8$ & 187 & $18 \cdot 5$ \\
\hline & Physically demanding & 133 & 76 & $18 \cdot 9$ & 57 & $5 \cdot 6$ \\
\hline & Very physically demanding & 28 & 20 & $5 \cdot 0$ & 8 & $0 \cdot 8$ \\
\hline & Missing $\S$ & 302 & 78 & - & 224 & - \\
\hline
\end{tabular}

Significant differences between the two clusters: $+P<0.05,+t+P<0.001$.

$\neq$ \$US $1=\$$ HK $7 \cdot 8$.

$\S$ Missing values are not included in column percentages.

$22 \cdot 7 \%$ attained only primary education, while $18 \cdot 0 \%$ had a bachelor's degree or above). Table 3 shows that the two clusters differed in age group, sex, smoking, income and PA required at work. The active cluster had a higher proportion of middle-aged participants (ages 35-54 years), while the proportions of adolescents and the elderly were higher in the less active cluster. There were more males (57.5\%) in the active cluster and more females (58.5\%) in the less active cluster. The proportion of smokers was higher in the active cluster $(16 \cdot 8 \% v .11 \cdot 5 \%$ in the less active cluster, $\mathrm{OR}=1 \cdot 55, P<0 \cdot 001)$. Classifying smokers by sex, it was found that the proportion of males who smoked was higher in the active cluster than in the less active cluster $(26.4 \% v .19 \cdot 0 \%, \mathrm{OR}=1 \cdot 53, P<0 \cdot 001)$, while for female smokers this pattern was reversed $(3 \cdot 1 \%$ v. $4 \cdot 4 \%, \mathrm{OR}=0 \cdot 70, P<0 \cdot 05)$. Monthly personal income groups (in Hong Kong dollars; \$US $1=\$ H K$ 7·8) were differently distributed in the two clusters, particularly in 
Table 4 Prevalence (\%) of chronic health conditions and obesity in the FAMILY Project Cohort Study, Hong Kong, 2009

\begin{tabular}{|c|c|c|c|c|c|c|}
\hline & \multicolumn{2}{|c|}{ Prevalence (\%) } & \multirow[b]{2}{*}{ OR $\ddagger$} & \multirow[b]{2}{*}{$95 \% \mathrm{Cl}$} & \multirow[b]{2}{*}{ Adjusted OR $\ddagger$, } & \multirow[b]{2}{*}{$95 \% \mathrm{Cl}$} \\
\hline & $\begin{array}{c}\text { Cluster } 1 \\
\text { (active; } n \text { 480) }\end{array}$ & $\begin{array}{c}\text { Cluster } 2 \\
\text { (less active; } n \text { 1234) }\end{array}$ & & & & \\
\hline $\begin{array}{l}\text { No chronic health condition } \\
\text { Chronic health conditions }\end{array}$ & $81 \cdot 82$ & $72 \cdot 67$ & 0.59 & $0 \cdot 45,0.78$ & $0 \cdot 62$ & $0 \cdot 46,0 \cdot 84$ \\
\hline Cancer & 0.45 & 1.55 & $3 \cdot 45$ & $0.80,14.94$ & $3 \cdot 37$ & $0 \cdot 71,16 \cdot 04$ \\
\hline Diabetes mellitus & $4 \cdot 09$ & $5 \cdot 26$ & $1 \cdot 30$ & $0 \cdot 76,2 \cdot 23$ & $1 \cdot 35$ & $0 \cdot 77,2 \cdot 38$ \\
\hline High blood pressure & $10 \cdot 00$ & $14 \cdot 14$ & $1 \cdot 48$ & $1 \cdot 04,2 \cdot 11$ & $1 \cdot 21$ & $0 \cdot 82,1 \cdot 79$ \\
\hline High cholesterol/TAG & $6 \cdot 14$ & $10 \cdot 09$ & $1 \cdot 72$ & $1 \cdot 11,2 \cdot 65$ & 1.52 & $0 \cdot 96,2 \cdot 42$ \\
\hline Heart disease & 0.68 & $2 \cdot 07$ & 3.08 & $0.92,10.27$ & $2 \cdot 54$ & $0 \cdot 71,9 \cdot 16$ \\
\hline Stroke & 0.23 & 1.03 & 4.59 & $0 \cdot 60,35 \cdot 40$ & 3.97 & $0 \cdot 50,31 \cdot 71$ \\
\hline Asthma & 0.68 & $2 \cdot 33$ & $3 \cdot 47$ & $1 \cdot 05,11 \cdot 50$ & $4 \cdot 48$ & $1 \cdot 02,19 \cdot 65$ \\
\hline COPD & 0.91 & 0.69 & $0 \cdot 76$ & $0.23,2 \cdot 53$ & $1 \cdot 29$ & $0 \cdot 32,5 \cdot 24$ \\
\hline \multicolumn{7}{|l|}{ Obesity\| } \\
\hline BFP & $37 \cdot 13$ & $43 \cdot 79$ & $1 \cdot 32$ & $1 \cdot 04,1 \cdot 67$ & $1 \cdot 12$ & $0 \cdot 87,1 \cdot 44$ \\
\hline BMI & $7 \cdot 20$ & $6 \cdot 32$ & $0 \cdot 87$ & $0.55,1.37$ & 0.89 & $0.55,1.42$ \\
\hline
\end{tabular}

COPD, chronic obstructive pulmonary disease; BFP, body fat percentage.

$\ddagger$ Reference category for the odds ratio: cluster 2 .

§Adjusted for age, sex, smoking, education and income.

IIIndicators of obesity: BFP $\geq 25 \%$ (males), $\geq 35 \%$ (females); BMI $\geq 30 \mathrm{~kg} / \mathrm{m}^{2}$.

lower-income brackets. In the active cluster, $24 \cdot 0 \%$ and $30.0 \%$ of the participants were in the \$HK $1-5000$ and \$HK 5001-10000 group, respectively, while in the less active cluster these numbers were $39.0 \%$ and $18.2 \%$, respectively (OR $=0.74$ and 1.93 , both $P<0.001)$. Finally, more participants had physically demanding jobs in the active cluster than in the other cluster $(P<0 \cdot 001)$.

\section{Healtb profile of the clusters}

The odds of having any of the eight chronic conditions in the less active cluster was 1.62 times $(=1 / 0.62)$ that in the active cluster (95\% CI $1 \cdot 20,2 \cdot 20)$, adjusted for age, sex, smoking, education and income (Table 4 ). The odds of having been diagnosed with cancer, diabetes, heart disease, stroke or asthma for the less active cluster were more than twice those for the active, although statistical significance was observed only for asthma $(P=0 \cdot 049)$. The prevalence of obesity was similar in both clusters regardless of the criterion used to define obesity (Table 4).

\section{Discussion}

We identified two temporal PA patterns in this Hong Kong population by using cluster analysis on hourly accelerometer data. The active cluster had higher overall PA levels than the other and a distinctive weekend PA pattern with clear peaks at certain hours. In contrast, the less active cluster had similar temporal patterns on weekdays and weekends. The two clusters differed in counts per minute by 204.4 (the equivalent of daily PA of an American woman aged 60 years or above $)^{(17)}$.

In summary, middle-aged people, males, smokers, the middle-income group and those having physically demanding jobs were more likely to be in the active cluster, consisting of one-quarter of the sample. These clear differences in demographic characteristics between the two clusters are discussed as follows. First, middleaged participants, aged 35-54 years, were prominently represented in the active cluster, whereas the less active cluster had more of the younger and older participants (ages $15-34$ years and $\geq 55$ years). The variable age distribution of the less active group suggests a need for different approaches in developing age-specific intervention programmes. A similar age difference was found in an accelerometer study of PA in the USA, in which those aged $40-49$ years were the most active group ${ }^{(34)}$. This may reflect the pandemic of sedentary lifestyles (e.g. screen time) among adolescents worldwide. Second, and surprisingly, in our sample the proportion of male smokers was higher in the active than in the less active group, contrary to a previous study in China ${ }^{(16)}$. This is because smokers were more likely to have physically demanding jobs than non-smokers. In the present study, $18 \cdot 5 \%(=34 / 184)$ of the smokers had a physically demanding job, compared with $10 \cdot 1 \% \quad(=118 / 1174)$ among non-smokers. Third, the income distribution was significantly different between the two clusters. In particular, the proportion of lower-income groups was higher in the less active cluster than in the active cluster. A possible explanation for this is that a large proportion of females $(346 / 777$ or $44.5 \%)$ were in lower-income brackets, and they may be housewives with part-time jobs $(169 / 346$ or $48.8 \%$ of them had full-time jobs) and less time for exercise or sports activities. In addition, it is possible that some males $(19 \cdot 2 \%=118 / 614)$ in the low-income group of \$HK 5001-10000 may have shorter workdays (hence a lower chance of working on weekends) that allows them to exercise on weekends. Fourth, the proportion of participants having a physically demanding job was significantly higher in the active cluster than in the less active cluster. This finding further 
supported the cluster solution as participants with a physically demanding job were in general more active than those with a less physically demanding job during weekdays $(392.5$ v. $289 \cdot 2$ counts $/ \mathrm{min}, P<0 \cdot 001)$.

The two clusters did not differ regarding other demographic variables, some of which had previously been reported to be associated with PA levels. One such variable was education: lower education level was associated with lower PA level among US and Swedish males ${ }^{(10)}$ and Chinese adults ${ }^{(16)}$, but not in our sample. This was perhaps because PA in Hong Kong is mostly not in the form of choosing to exercise for personal fitness, but is more related to the virtually universal use of public transportation (which always involves some walking). Another such variable was BMI ${ }^{(10,16)}$. Other studies of PA pattern, mostly among children, found that higher BMI was associated with lower PA levels ${ }^{(8,21,35-37)}$. This association was not found in our study, again perhaps because much of the PA in Hong Kong relates to routine transportation that is undertaken regardless of body weight. The other inconsistency regarded alcohol usage. Alcohol consumption has been linked to higher PA level among adults $^{(38)}$ and college students ${ }^{(39)}$ in the USA, but there was only a non-significant difference in our sample.

\section{Strengths and limitations}

The present study offered a large sample from a Westernized and urbanized Asian population that complements the picture obtained from existing studies in European and North American samples. It used cluster analysis to analyse accelerometer data, with which we could identify PA patterns that are specific to certain times of the day.

A limitation of the study concerned sample representativeness. While it began from a random population sample, the inclusion criteria required at least $12 \mathrm{~h}$ of recorded time daily for four consecutive days, which entailed some loss of respondents and a potential selection bias. It is likely that the PA patterns for those who provided four valid days of accelerometer data were different from those who do not. While the study provides useful descriptive data, its major limitation lies in the cross-sectional design. The association of PA with chronic health conditions cannot demonstrate causality, as chronic conditions could have limited the ability to exercise ${ }^{(40)}$. Nevertheless, the findings regarding the association of PA with chronic health problems are important, as they may raise the priority of promoting PA among those with chronic health conditions.

\section{Conclusions}

The present study has broadened the scope of research on PA patterns and shed light on the potential of using accelerometer data and PA patterns to classify individuals in more precise categories, e.g. active on weekends, sedentary in the morning, etc. It has also contributed to the understanding of PA patterns of Hong Kong Chinese, the most Westernized and urbanized city of China, by identifying two clusters, one more active than the other. Neither cluster showed signs of regularly increased PA (implying exercise or sports activity) on weekdays, most probably reflective of the intense pace in city life. Therefore, we suggest that potential interventions to promote PA in Hong Kong may be most effective in targeting those who are sedentary on weekends. Providing free weekend PA programmes may also help increase participation rates. Further research is needed to refine the classification of PA patterns and establish standard cut-off points. Also, future study is needed to examine the predictive power of different PA patterns on long-term health outcomes.

\section{Acknowledgements}

The present study was a part of the project 'FAMILY: a Jockey Club Initiative for a Harmonious Society' supported by The Hong Kong Jockey Club Charities Trust. The funding body played no part in the data analysis, drafting of the manuscript, or the decision to submit for publication. The authors declare that they have no conflict of interest. P.H.L. conducted the data analysis and drafted the manuscript. Y.-Y.Y. performed the data collection including quality control. I.M., G.M.L. and T.H.L. designed the study and planned the analysis strategy. All authors reviewed and approved the manuscript. The authors sincerely thank Dr Wilson W.S. Tam, Dr Ben K.K. Li and Mr Paul T.K. Wong (School of Public Health, The University of Hong Kong) for their role in the development of the survey instruments and the preparatory work for this research.

\section{References}

1. Janssen I \& LeBlanc AG (2010) Systemic review of the health benefits of physical activity and fitness in schoolaged children and youth. Int J Behav Nutr Phys Act 7, 40.

2. Buman MP, Hekler EB, Haskell WL et al. (2010) Objective light-intensity physical activity associations with rated health in older adults. Am J Epidemiol 172, 1155-1165.

3. Bize R, Johnson JA \& Plotnikoff RC (2007) Physical activity level and health-related quality of life in the general adult population: a systematic review. Prev Med 45, 401-415.

4. Roberts CK \& Barnard RJ (2005) Effects of exercise and diet on chronic disease. J Appl Physiol 98, 3-30.

5. Pedersen BK \& Saltin B (2006) Evidence for prescribing exercise as therapy in chronic disease. Scand J Med Sci Sports 16, Suppl. 1, 3-63.

6. Ortega FB, Ruiz JR, Labayen I et al. (2011) Sleep duration and activity levels in Estonian and Swedish children and adolescents. Eur J Appl Physiol 111, 2615-2623.

7. Nader PR, Bradley RH, Houts RM et al. (2008) Moderateto-vigorous physical activity from ages 9 to 15 years. JAMA 300, 295-305. 
8. Ness AR, Leary SD, Mattock C et al. (2007) Objectively measured physical activity and fat mass in a large cohort of children. PLOS Med 4, e97.

9. Riddoch CJ, Mattock C, Deere K et al. (2007) Objective measurement of levels and patterns of physical activity. Arch Dis Child 92, 963-969.

10. Hagströmer M, Trost SG, Sjöström M et al. (2010) Levels and patterns of objectively assessed physical activity a comparison between Sweden and the United States. Am J Epidemiol 171, 1055-1064.

11. Pate RR, Pratt M, Blair SN et al. (1995) Physical activity and public health. JAMA 273, 402-407.

12. Guthold R, Ono T, Strong KL et al. (2008) Worldwide variability in physical inactivity: a 51-country survey. Am J Prev Med 34, 486-494.

13. Lee PH, Macfarlane DJ, Lam TH et al. (2011) Validity of the International Physical Activity Questionnaire Short Form (IPAQ-SF): a systematic review. Int J Behav Nutr Phys Act 8, 115.

14. van Poppel MNM, Chinapaw MJM, Mokkink LB et al. (2010) Physical activity questionnaires for adults: a systematic review of measurement properties. Sports Med 40, 565-600.

15. Ferrari P, Friedenreich C \& Matthews CE (2007) The role of measurement error in estimating levels of physical activity. Am J Epidemiol 166, 832-840.

16. Peters TM, Moore SC, Xiang YB et al. (2010) Accelerometermeasured physical activity in Chinese adults. Am J Prev Med 38, 583-591.

17. Troiano RP, Berrigan D, Dodd KW et al. (2008) Physical activity in the United States measured by accelerometer. Med Sci Sports Exerc 40, 181-188.

18. Hastie T, Tibshirani R \& Friedman J (2008) The Elements of Statistical Learning: Data Mining, Inference, and Prediction. New York: Springer-Verlag.

19. Monda KL \& Popkin BM (2005) Cluster analysis methods help to clarify the activity-BMI relationship of Chinese youth. Obes Res 13, 1042-1051.

20. Rovniak LS, Sallis JF, Saelens BE et al. (2010) Adults' physical activity activity patterns across life domains: cluster analysis with replication. Health Psychol 29, 496-505.

21. Page A, Cooper AR, Stamatakis E et al. (2005) Physical activity patterns in nonobese and obese children asessed using minute-by-minute accelerometry. Int J Obes (Lond) 29, 1070-1076.

22. Yu XN, Tam WWS, Wong PTK et al. (2012) The Patient Health Questionnaire-9 for measuring depressive symptoms among the general population in Hong Kong. Compre Psychiatry 53, 95-102.

23. Reilly JJ, Penpraze V, Hislop J et al. (2008) Objective measurement of physical activity and sedentary behaviour: review with new data. Arch Dis Child 93, 614-619.
24. Rothney MP, Apker GA, Song Y et al. (2008) Comparing the performance of three generations of ActiGraph accelerometers. J Appl Physiol 105, 1091-1097.

25. de Vries SI, Bakker I, Hopman-Rock R et al. (2006) Clinimetric review of motion sensors in children and adolescents. J Clin Epidemiol 59, 670-680.

26. McClain JJ, Dodd KW, Berrigan D et al. (2010) How many accelerometer days are needed for stable population and individual weekly activity estimates? Med Sci Sports Exerc 42, Suppl. 5, S117-S118.

27. Jakicic JM, Gregg EW, Knowler W et al. (2010) Activity patterns of obese adults with type 2 diabetes in the Look AHEAD Study. Med Sci Sports Exerc 42, 1995-2005.

28. Ward DS, Evenson KR, Vaughn A et al. (2005) Accelerometer use in physical activity: best practices and research recommendations. Med Sci Sports Exerc 37, 11 Suppl., S582-S588.

29. Freedson P, Melanson E \& Sirard J (1998) Calibration of the computer science and applications, inc. accelerometer. Med Sci Sports Exerc 30, 777-781.

30. Lloyd SP (1982) Least squares quantization in PCM. IEEE Trans Inform Theory 28, 129-137.

31. Thorndike RL (1953) Who belong in the family? Psychometrika 18, 267-276.

32. Cho HJ, Kim YJ, Jung HJ et al. (2008) OutlierD: an $\mathrm{R}$ package for outlier detection using quantile regression on mass spectrometry data. Bioinformatics 24, 882-884.

33. Cohen J (1988) Statistical Power Analysis for the Behavioral Sciences, 2nd ed. Hillsdale, NJ: Lawrence Erlbaum Associates.

34. Tucker JM, Welk GJ \& Beyler NK (2011) Physical activity in US adults: compliance with the physical activity guidelines for Americans. Am J Prev Med 40, 454-461.

35. Stevens J, Murray DM, Baggett CD et al. (2007) Objectively assessed associations between physical activity and body composition in middle-school girls. Am J Epidemiol 166, 1298-1305.

36. Basterfield L, Adamson AJ, Frary JK et al. (2011) Longitudinal study of physical activity and sedentary behavior in children. Pediatrics 127, e24-e30.

37. Metcalf BS, Voss LD, Hosking J et al. (2008) Physical activity at the government-recommended level and obesity-related health outcomes: a longitudinal study (Early Bird 37). Arch Dis Child 93, 772-777.

38. Gordon-Larsen P, Boone-Heinonen J, Sidney S et al. (2009) Active commuting and cardiovascular disease risk. Arch Intern Med 169, 1216-1223.

39. Musselman JRB \& Rutledge PC (2010) The incongruous alcohol-activity association: Physical activity and alcohol consumption in college students. Psychol Sport Exerc 11, 609-618.

40. van den Berg-Emons RJ, Bussmann JB \& Stam HJ (2010) Accelerometry-based activity spectrum in persons with chronic physical conditions. Arch Phys Med Rehabil 91, 1856-1861. 